\title{
Oral Microbiota and Cancer Development
}

\author{
Heidi Tuominen ${ }^{\mathrm{a}}$ b Jaana Rautava ${ }^{\mathrm{a}, \mathrm{c}}$ \\ ${ }^{a}$ Department of Oral Pathology and Oral Radiology, Institute of Dentistry, Faculty of Medicine, University of

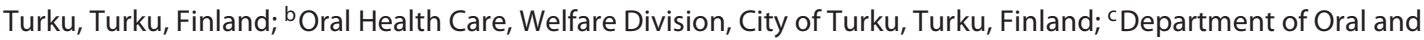 \\ Maxillofacial Diseases, Clinicum, Faculty of Medicine, University of Helsinki and Helsinki University Hospital, \\ Helsinki, Finland
}

\section{Keywords}

Oral cavity $\cdot$ Mucosa $\cdot$ Cancer $\cdot$ Carcinoma $\cdot$ Oral cancer .

Bacteria $\cdot$ Microbiota $\cdot$ Microbiome

\begin{abstract}
Oral microbiota are among the most diverse in the human body. More than 700 species have been identified in the mouth, and new sequencing methods are allowing us to discover even more species. The anatomy of the oral cavity is different from that of other body sites. The oral cavity has mucosal surfaces (the tongue, the buccal mucosa, the gingiva, and the palate), hard tissues (the teeth), and exocrine gland tissue (major and minor salivary glands), all of which present unique features for microbiota composition. The connection between oral microbiota and diseases of the human body has been under intensive research in the past years. Furthermore, oral microbiota have been associated with cancer development. Patients suffering from periodontitis, a common advanced gingival disease caused by bacterial dysbiosis, have a 2-5 times higher risk of acquiring any cancer compared to healthy individuals. Some oral taxa, especially Porphyromonas gingivalis and Fusobacterium nucleatum, have been shown to have carcinogenic potential by
\end{abstract}

several different mechanisms. They can inhibit apoptosis, activate cell proliferation, promote cellular invasion, induce chronic inflammation, and directly produce carcinogens. These microbiota changes can already be seen with potentially malignant lesions of the oral cavity. The causal relationship between microbiota and cancer is complex. It is difficult to accurately study the impact of specific bacteria on carcinoma development in humans. This review focuses on the elucidating the interactions between oral cavity bacterial microbiota and cancer. We gather literature on the current knowledge of the bacterial contribution to cancer development and the mechanisms behind it. $\bigcirc 2020 \mathrm{~S}$. Karger AG, Basel

\section{Introduction}

Healthy bacterial microbiota and homeostasis between the human host and microbiota is important for normal human body function [1]. The microbiota interacts with several human body functions. It can, e.g., modulate immune responses, modify the food intake, affect appetite, take part in vitamin biosynthesis, protect humans from exogenous pathogens, and produce some an-

karger@karger.com
www.karger.com/pat
Karger ${ }^{\prime /}$

Jaana Rautava

Department of Oral and Maxillofacial Diseases

Clinicum, Faculty of Medicine, University of Helsinki

Kytösuontie 9, FI-00300 Helsinki (Finland)

jaana.rautava@helsinki.fi 
timicrobial substances [2]. These effects are considered beneficial, and life without bacteria would not be the same - and maybe not even possible [1]. If microbiota homeostasis is distorted and some pathogenic bacteria becomes more prevalent, disease may occur.

When abnormalities occur in an otherwise balanced system, the term dysbiosis is used. However, the microbiota are continually changing as a result of internal and external stimuli. Therefore, it is difficult to investigate and understand the complex nature of microbiota-host interactions and the triggers of disease onset in the human body. Despite this fact, several different diseases have been connected to alterations in microbiota composition. It has been suggested that alterations in the bacterial microbiota composition might affect at least the onset of inflammatory bowel disease, type 1 and type 2 diabetes, obesity, allergies, asthma, autism, and Alzheimer disease [2-11].

The interaction between an individual's microbiota and the environment is dynamic. Individually there are usually no major fluctuations in the microbiota composition over time [12]. Between individuals the microbiota composition varies according to age, sex, and diet in health and disease, in addition to geographical variations $[13,14]$. The human microbiota starts to develop gradually before and after the delivery [15-17]. Most of these initial changes in the bacterial microbiota composition start to settle after some months of life, also in the oral cavity [18-28].

Bacterial dysbiosis in the adult oral cavity can cause, e.g., gingivitis, periodontitis, dental caries (tooth decay), and endodontic abscesses. Nevertheless, due to the continuous interplay between microbiota and the human host's immune response, acute infections in the oral cavity are rather rare taking into consideration the dense microbial colonization [29-32]. Besides this, oral bacteria have been implicated in numerous systemic diseases as well. Oral cavity-linked bacterial species have been found in bacterial endocarditis, aspiration pneumonia, osteomyelitis, rheumatoid arthritis, and cardiovascular disease [33-36]. Furthermore, poor oral hygiene and periodontitis have been associated with an increased risk of oral squamous cell carcinoma (OSCC) [37].

The prevalence of OSCC is increasing, but it has been detected to be highly variable according to gender, behavior (etiological factors), and geography [38]. While the treatment has improved in recent years, an early diagnosis remains very important for a better prognosis [39]. Unfortunately, patients treated with the first primary OSCC have a high risk of developing recurrent or second-

Oral Microbiota and Cancer Development ary primary OSCC [40]. This has been explained by field cancerization, which is caused by long-term use of tobacco products and/or heavy alcohol use [41]. Another explanation might be the oral cavity bacterial microbiota composition that could have contributed to a malignant transformation in the first place.

OSCC does not often present any major symptoms, but it is easily detectable via direct examination. Therefore, it is vitally important for the oral cavity mucosa to be screened regularly by an experienced (dental) professional, especially for patients with risky behavior $[42,43]$. OSCC is a relatively rapidly progressing carcinoma and it metastasizes early to local neck lymph nodes [44-46]. The most often seen clinical lesion are symptomless nonhealing ulcers [43]. Pain is a late symptom [42, 43]. Tobacco and alcohol consumption are known risk factors for OSCC, accounting for a population-attributable risk of $74 \%$ [37]. It has been estimated that some $15 \%$ of OSCC are of unknown origin, e.g., from bacterial microbiota contribution [47].

This review focuses on oral cavity bacterial microbiota and the known interactions between oral cavity microbiota and OSCC. We have excluded oropharynx-related diseases and other cancer entities such as salivary gland tumors, cancers of the lymphatic tissues, and metastatic manifestations. In addition, the oral cavity anatomy and healthy oral bacterial microbiota are presented. We also describe some significant oral diseases and conditions that may precede OSCC progression.

\section{The Anatomy of the Oral Cavity}

The oral cavity begins from the mucosa of the lips. On the palate, the hard palate belongs to the oral cavity and the soft palate belongs to the pharynx. Similarly, the mobile (oral) tongue is part of the oral cavity and the base of the tongue behind the vallate and the foliate papillae is the pharynx.

The anatomy of the oral cavity is exceptional compared to that of other human body sites. A unique feature is hard tissue, i.e., teeth that protrude through the mucosa covering a major part of the oral cavity. Teeth provide nonshedding surfaces for distinct bacterial biofilm formation, whereas mucosal surfaces are continuously renewing and older epithelial layers are shedding from the surface, presenting challenges to permanent bacterial colonization.

The oral mucosal surfaces differ according to anatomical location; roughly it can be divided to masticatory and 
nonmasticatory mucosa. Masticatory mucosa, also known as keratinized stratified squamous epithelium, is found from the attached gingiva around the teeth, the hard palate, and the tongue's upper surface. The tongue's upper surface is, in addition, embedded with lingual papillae with taste buds. Everywhere else, the mucosa in the oral cavity is called nonmasticatory mucosa or stratified squamous nonkeratinized epithelium at buccal and labial sites as well as at the floor of the mouth. In cases of continuous trauma, the nonkeratinized epithelium can transform into keratinized epithelium by nonneoplastic hyperkeratinization [48-50].

Teeth are hard calcified structures that are in close contact with mucosa in the oral cavity. This unique structure cannot be found anywhere else in the human body. Babies are born without teeth, and the first primary (deciduous) teeth erupt usually around the age of 6 months. The transition to permanent teeth starts at around 7 years of age and continues until the early 20 s (wisdom teeth). Between the teeth and the mucosal gingiva is the gingival sulcus, which is an important anatomical site for bacterial biofilm formation, i.e., plaque $[51,52]$.

One important aspect of oral cavity health is saliva production. Saliva is produced from the major and minor salivary glands. The major salivary gland openings are located on the floor of the mouth (i.e. sublingual caruncles) and in the buccal mucosa, known as the Stensen duct. Around 1-2 L of saliva are produced and swallowed daily [52]. Saliva is mainly composed of water, electrolytes, mucus, antibacterial compounds (such as IgA), and enzymes that help to digest food and kill bacteria $[53,54]$. Saliva function is critically important to maintain oral health. Without saliva, the prevalence of oral bacteriumrelated diseases (such as dental caries, gingivitis, and periodontitis) increases significantly $[53,54]$.

\section{The Healthy Oral Microbiota}

The Human Oral Microbiome Database (HOMD) lists the most prevalent phyla in the adult human oral cavity as being composed of Firmicutes, Bacteroidetes, Proteobacteria, Actinobacteria, and Fusobacteria $[30,55,56]$. This has also been corroborated in other studies $[35,57]$. In March 2020 the HOMD listed 784 different bacterial taxa and 1,567 genomes detected in the human oral microbiome taxonomic hierarchy (HOMD, www.homd. org). The majority of these belong to the Firmicutes phylum (266 taxa and 588 genomes) and furthermore to the Streptococcaceae family ( 38 taxa and 200 genomes).
The total volume of oral bacteria is around $10^{11}$ bacte$\mathrm{ria} / \mathrm{mL}$ [30-32]. The main genus in the oral cavity is Streptococcus, in addition to Haemophilus, Leptotrichia, Porphyromonas, Prevotella, Propionibacterium, Staphylococcus, Veillonella, and Treponema [30, 35, 56, 57]. Nonetheless, some bacterial species are more site specific while others can flourish in multiple locations simultaneously $[35,55]$. Oral microbiota present the lowest $\beta$ diversity but the highest $\alpha$ diversity compared to other body sites, and there are only few alterations in oral cavity microbiota composition between different individuals [51,55]. Since the oral cavity is under constant exposure to exogenous microorganisms while eating, drinking, and breathing, it is not always easy to determine which specific species are indigenous and which are only transient [30]. In addition, oral microbiota vary according to age, gender, and even level of education [58]. Nevertheless, once established, oral microbiota remain relatively stable [59].

The HOMD also provides information about the oral anatomical site-specific bacterial composition (Fig. 1) $[30,35]$. Nonetheless, oral bacteria can somewhat freely translocate from subgingival sites and other niches with saliva [60].

As mentioned earlier, this review focuses on bacterial microbiota and the known interactions between bacteria and cancer development. Furthermore, microbes other than bacteria can contribute to cancer development. For example, in the oral cavity, persistent oral fungi infections (mainly with Candida spp.), persistent high-risk human papillomavirus (HPV) infection, and Epstein-Barr virus (EBV) infection can be involved in oncogenic mutation formation, leading to OSCC development [61-63]. Highrisk HPV DNA has been detected already in newborns [64], but it is not known how this early HPV oral positivity can affect health later in life. These different microbes may interact. We have shown differences in bacterial microbiota composition in the oral cavity in oral-HPV-positive women and neonates compared to HPV-negative individuals [64].

\section{Periodontal Disease}

Periodontitis is classified as an advanced inflammatory gingival disease caused by bacterial dysbiosis and eventually it can lead to tooth loss $[67,68]$. It starts as gingival bleeding in response to inflammation to bacterial biofilm accumulation (plaque) around the tooth marginal gingival surfaces [69]. Periodontitis develops over years 
Fig. 1. Most abundant bacterial species in oral cavity according to different anatomical areas $[35,55,65,66]$.

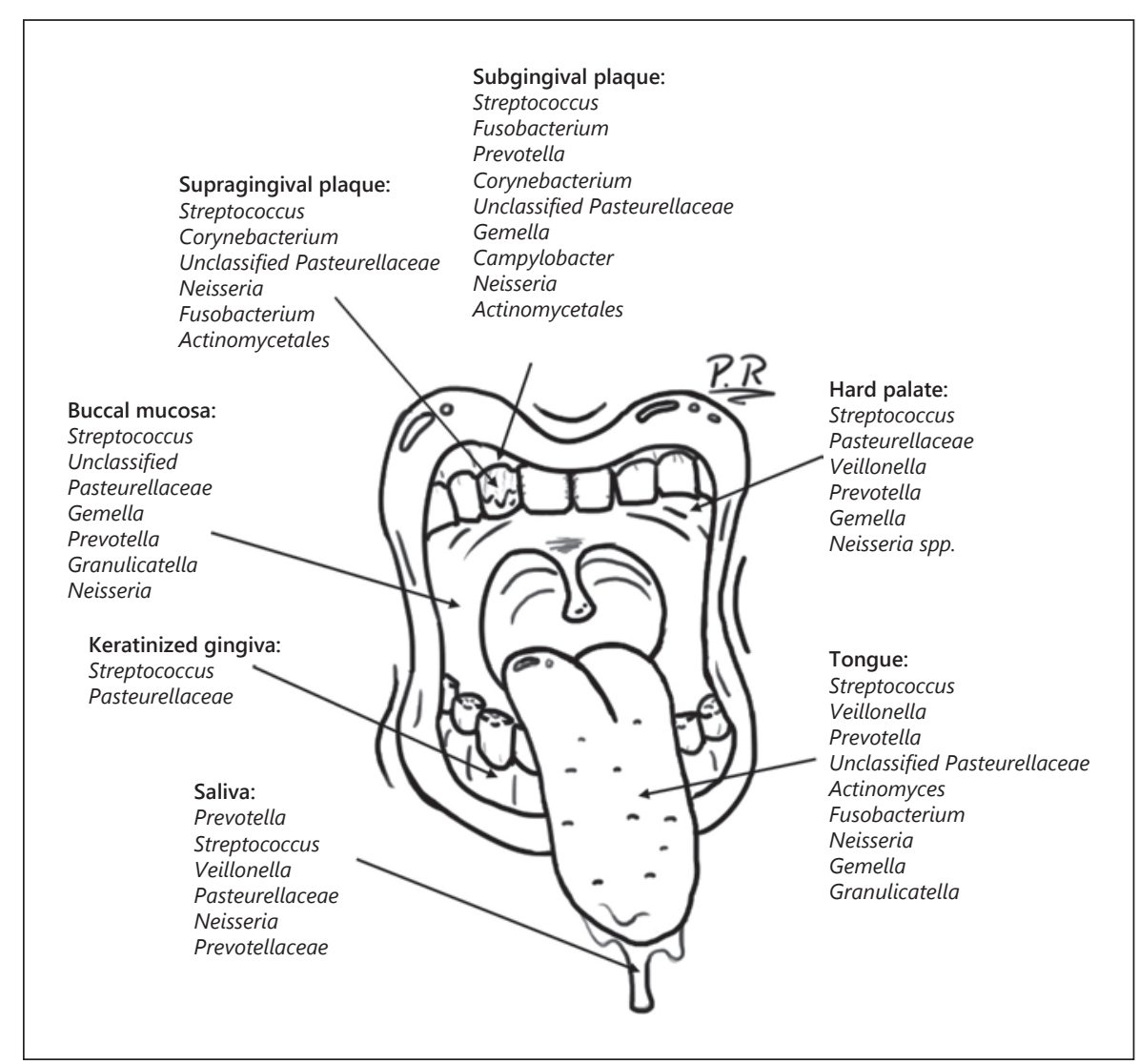

when dental plaque continues to accumulate, leading to the formation of periodontal pockets and tissue destruction, and it is therefore classified as a chronic infection [69]. If this chronic disease is left untreated, it maintains low-level inflammation and increases blood CRP levels $[70,71]$. Periodontitis is a relatively common oral disease; it is estimated that the majority of adults (50-70\%) present some clinical symptoms of periodontal disease [72].

Known periodontal pathogens, such as Tannerella forsythia, $P$. gingivalis, and Treponema denticola, are not usually detected in oral cavities of healthy humans [35]. The literature in fact presents a unique set of so-called periodontal pathogens. This unit consists of Aggregatibacter actinomycetemcomitans, $P$. gingivalis, T. forsythia, T. denticola, Prevotella intermedia, P. nigrescens, Parvimonas micra, Campylobacter rectus, and Fusobacterium nucleatum $[56,73,74]$. But, as these species sometimes can be detected in healthy individuals it has become obvious that the dysbiosis and the relative abundance of pathological species is the main trigger of disease onset [7577]. Furthermore, multiple bacteria, rather than a single bacterium, work synergistically.

Oral Microbiota and Cancer Development
Patients suffering from periodontitis have a 2-5 times higher risk of acquiring any cancer compared to healthy controls, even among patients who have never smoked $[68,78-81]$. The correlation to OSCC in particular seems to be consistent [57, 69, 81-84]. Thus, an increased number of missing teeth, as a sign of periodontitis, has been linked to a higher OSCC prevalence $[69,84-86]$.

The elevated cancer risk of periodontitis patients is thought to be associated with differences in the oral bacterial microbiota composition. These periodontopathogenic bacteria (especially $P$. gingivalis, $P$. intermedia, and F. nucleatum) enable and maintain constant chronic infection and the systemic inflammation response $[57,69$, $82-84,87-90]$. The bacterial impacts are mainly indirect changes observed based on increased levels of leukocytes and cytokines after the initial inflammatory response [89, 91]. Some periodontal pathogens can also directly affect specific intracellular pathways, promote cell survival, activate oncogenic pathways, reduce proapoptotic protein expression, and increase cell migration and invasion, in addition to enhancing metastasis [89]. P. gingivalis and $F$. nucleatum can additionally activate cell transformation 
[82, 89, 92-95]. Other periodontal pathogens, i.e., A. actinomycetemcomitans, T. forsythia, and T. denticola, can produce virulence factors that induce the release of proinflammatory cytokines [57].

All of these changes in chronic periodontal disease maintain the chronic inflammation process and destruction of periodontal tissue. These alterations at the cellular level can furthermore induce permanent genetic alterations in epithelial cells [57]. After several years this continuous exposure to cell metabolites can trigger abnormal cell divisions and eventually even carcinoma development [68].

\section{Oral Potentially Malignant (Precursor) Mucosal Lesions}

The World Health Organization has classified a number of oral lesions as potentially malignant (precursor) lesions for OSCC [96]. Lichen planus, leukoplakia, and erythroplakia are the most often encountered clinical manifestations in the human oral cavity, and these patients that are known to have a somewhat higher risk of malignant transformation compared to their healthy counterparts [57].

\section{Oral Lichen Planus}

Oral lichen planus (OLP) is a chronic inflammatory mucosal disease of unknown origin [97]. Some 0.1-4.0\% of the population is estimated to have OLP lesions (females more than males), and most of the lesions are asymptomatic $[98,99]$. OLP is known to be potentially malignant, and around $1.0-3.0 \%$ of the lesions progress to OSCC [99-101]. It is important to regularly check OLP patients in order to detect suspicious changes early. Some OLP patients do not require any treatment, while others benefit from local corticosteroid treatment. Occasionally, some patients experience symptom relief and diminished clinical lesions with chlorhexidine mouthwash alone, which suggests a bacterial contribution to the disease [102].

As a matter of fact, oral bacterial dysbiosis has been detected in OLP patients [73, 103]. Higher levels of Porphyromonas and Solobacterium and P. melaninogenica have been observed in OLP patients, with a significantly lower abundance of Haemophilus, Corynebacterium, Cellulosimicrobium, and Campylobacter compared to the healthy control group [73]. Furthermore, another study detected more abundant Fusobacterium, Leptotrichia, and Lautotropia in OLP lesions, while Streptococcus was detected more in healthy patients [103]. Porphyromonas has been correlated with the severity of OLP [73]. Nevertheless, the possible causative role of bacteria in OLP and/ or malignant transformation has not yet been elucidated [104].

\section{Leukoplakia and Erythroplakia}

Leukoplakia is defined as a whitish lesion on the oral mucosa that is not related to any other specific disease and is mainly being asymptomatic $[99,105]$. Erythroplakia, on the other hand, is a similar red lesion of the oral mucosa [99]. Both leukoplakia and erythroplakia are clinical terms and the diagnosis must be confirmed by biopsy and histopathological analysis. The prevalence of leukoplakia is around $1.0-20.0 \%$ and that of erythroplakia is $0.01-0.2 \%[99,106,107]$. OSCC development is observed in $15.6-39.2 \%$ of cases with leukoplakias, while the rate is $51.0 \%$ in erythroplakias [99].

Leukoplakia has been detected to harbor more Haemophilus, Leptotrichia, Campylobacter, Rothia mucilaginosa, and Fusobacteria, with lower levels of Firmicutes $[108,109]$. No literature is currently available describing the potential bacterial microbiota changes observed in erythroplakia patients; this is probably due to the low prevalence of the condition.

\section{Tobacco and Ethanol}

Cigarette smoke contains hundreds of toxic chemicals. Regular smoking is known to increase individuals' risk of OSCC and other cancers, as well as chronic obstructive pulmonary disease, cardiovascular disease, and periodontitis [110, 111]. In addition, smoking directly affects oral mucosal sites and therefore also the oral bacterial composition. Smoking has been detected to reduce bacterial diversity ( $\alpha$ diversity), especially in buccal mucosa and by changing the bacterial composition favoring $R$. mucilaginosa, Streptococcus salivarius, and S. mitis [111, 112]. Furthermore, higher levels of Prevotella, Veillonella, and Leptotrichia have been observed in current smokers [113]. On the other hand, lower levels of F. nucleatum and Leptotrichia have been detected in patients who smoke and have OLP [108]. Nonetheless, the levels of $S$. mutans and Lactobacillus have been observed to be unchanged even with regular smoking [114]. Elevated levels of $R$. $m u$ cilaginosa, Veillonella, Streptococcus, and Leptotrichia have been connected to OSCC independently, without the presence of smoking $[47,108,113,115-118]$. 
Ethanol is not carcinogenic on its own, but its metabolites acetaldehyde, hydroxyl ethyl radicals, and hydroxyl radicals are [119]. Acetaldehyde has the potential to cause chromatic changes and point mutations to DNA and hyperproliferation of the epithelium $[106,120]$. Some known oral pathogens, such as R. mucilaginosa, Neisseria spp., and S. mitis, have been detected to be able to transform ethanol to acetaldehyde [121]. Also the endogenous production of acetaldehyde by oral bacteria is higher with poor oral hygiene [122].

\section{Oral Microbiota and OSCC}

The decrease in Firmicutes and increased levels of Fusobacteria have been linked to OSCC $[116,118]$. Significantly higher levels of Peptostreptococcus, Fusobacterium, Prevotella (especially P. melaninogenica), Porphyromonas, Veillonella (mainly Veillonella parvula), Haemophilus, Rothia, and Streptococcus have been detected in OSCC samples [47, 113, 115-117]. OSCC can be divided into different disease stages by the TNM (tumor, node, metastasis) classification [123]. These TNM stages of OSCC have been observed in significantly different oral bacterial microbiota compositions. Yang et al. [118] detected that levels of Streptococcus, Haemophilus, Porphyromonas, and Actinomyces decreased in carcinoma progression while $F$. periodonticum, P. micra, S. constellatus, Haemophilus influenza, and Filifactor alocis were associated with OSCC and their levels increased along with disease severity with the TNM classification. Furthermore, the most severe OSCC at stage 4 represented significantly more complex microbiota than those at lower stages. Differences have also been detected between precursor lesions and OSCC $[113,118]$. Severe dysplasia, before the onset of OSCC, has been associated with elevated levels of Leptotrichia spp. and C. concisus [108]. Zhang et al. [124] suggested 3 possible mechanisms behind these changes. Bacteria might influence tumorigenesis by: (1) stimulating chronic inflammation, (2) acting as an antiapoptotic agent, or (3) producing carcinogenic substances [124].

Strong evidence of two potentially carcinogenic oral bacteria has accumulated in recent years with in vitro and in animal models. $P$. gingivalis and $F$. nucleatum have both been shown to be able to induce the production of inflammatory cytokines, as well as cell proliferation and cellular invasion, in OSCC with various different mechanisms $[8,57,125,126]$. $P$. gingivalis was responsible for induction of the production of interleukins, tumor necrosis factor (TNF)- $\alpha$, and matrix metalloproteinases (MMP) and for inhibition of apoptosis [125]. It also prevented the activity of the p53 tumor suppressor gene $[57,125]$. Continued exposure to $P$. gingivalis has also been demonstrated to increase the invasiveness of OSCC [125].

F. nucleatum, on the other hand, was responsible for the promotion of cell proliferation and for the increase in the production of interleukins and other MMP that drive tumor invasion and metastasis [57, 125]. All of these changes resulted in an elevated transcriptional activity of oncogenes and proinflammatory cytokines [125]. Both of these bacteria, i.e., P. gingivalis and F. nucleatum, were able to release endotoxins, such as lipopolysaccharides, which in turn can activate inflammation-associated cytokine production. Inflammation-associated cytokine production is the major factor in bacteria-induced inflammation and a contributor to carcinogenesis [57, 127, 128].

The previous studies are observational studies or in vitro findings. However, there is also evidence of a bacterial contribution to tumorigenesis with an animal model. Stashenko et al. [129] colonized germ-free mice with different oral microbiomes and exposed them to a 4-NQO carcinogenic agent. Mice with oral microbiome and 4-NQO had more and larger OSCC compared to controls with only 4-NQO treatment.

\section{Oral Microbiota and Cancers of Other Body Sites}

Several specific oral pathogenic bacteria have been linked to cancers of other body sites, in addition to OSCC development. Since the oral cavity is the starting point of the digestive system, pathogenic bacteria may, e.g., disseminate via saliva from the oral cavity and have an impact on distant organs. It has been estimated that, on a daily basis, $10^{11}$ oral bacteria make their way through the digestive system [130]. Oral dysbiosis have been connected mainly to patients with tumors of the gastrointestinal tract and esophageal, gastric, pancreatic, and colorectal cancers [51, 131-134].

As previously discussed, bacteria, such as the periodontal pathogens $P$. gingivalis and F. nucleatum, have several different mechanisms via which they can interfere with cell signaling and cause tumorigenesis [126, 135]. These specific bacteria, in addition to Rothia, T. denticola, and $P$. intermedia, have been detected in colorectal cancer specimens where they are thought to cause disruption in the intestinal microbiota, ultimately causing dysbiosis $[51,131,136,137]$. Colorectal cancer has also been connected to Streptococcus and Prevotella, both oral bacterial species [131]. 
In addition, a higher prevalence of the periodontopathogens $P$. gingivalis, Porphyromonas, S. mitis, and A. actinomycetemcomitans in the oral cavity has been found to increase the risk of pancreatic cancer [132]. Periodontal disease itself, in general, elevates the risk of acquiring pancreatic cancer $[69,134,138,139]$. On the other hand, Fusobacteria showed protective association [132]. Inconsistent results have been detected with Leptotrichia according to different studies in pancreatic cancer patients' oral cavity $[132,140]$. Furthermore, higher levels of circulating $P$. gingivalis antibodies have been linked to a higher risk of pancreatic cancer [133, 140-142].

Peters et al. [143] found the oral periodontal pathogens $T$. forsythia and $P$. gingivalis to be more abundant in esophageal cancer. In addition, levels of $T$. denticola, $S$. mitis, and S. anginosus have also been detected to be increased in esophageal cancer patients [144].

\section{Discussion}

Accumulating evidence suggests a link between oral cavity bacterial microbiota and cancer. This is most widely shown with OSCC. However, OSCC is caused by multiple simultaneous factors [106] and the contribution of bacteria is difficult to separate from them [145]. As we have presented, there seem to be significant changes in the bacterial microbiota composition in the oral cavity either preceding or with OSCC. This can be seen already with potentially malignant precursor lesions, such as leukoplakia and OLP $[99,101,105,107-109,146]$. In addition, infection is a major cause of chronic inflammation which, on its own, facilitates increased cell proliferation, mutagenesis, and oncogene activation preceding OSCC development [147].

Periodontal disease and periodontopathogens have a known pathological impact not only on the teeth supporting connective and bone tissues but also on the human immune defence. It has a direct disturbing effect on cellsignaling pathways. These changes are known to predispose to cancer development [57, 68, 69, 82-84, 87-93, 95]. Nevertheless, since the causal relationship is complex, it is extremely difficult to accurately study the impact of specific bacteria on carcinoma development in humans.

Chronic inflammation, triggered by pathogenic bacteria infections, has a significant effect on carcinogenesis in several different stages, i.e., induction, progression, invasion, and metastasis [148]. It has been suggested that precisely chronic inflammation would be the missing link between bacteria and oral carcinogenesis [125]. This is demonstrated most clearly by the previously discussed periodontal pathogens $P$. gingivalis and $F$. nucleatum.

Many of the bacteria have been shown to be linked to potentially harmful mechanisms at the cellular level. However, it is not yet confirmed that these bacteria actually influence OSCC development in humans. [57, 68, 69, $82-84,87-93,95]$. Alterations of oral cavity bacterial microbiota communities could as a diagnostic tool to screen patients in the future and possibly even predict OSCC development. Especially the presence of $P$. gingivalis and $F$. nucleatum could predispose individuals to carcinogenesis, and these bacteria have been reported to be present at significantly higher levels in OSCC surfaces $[117,126]$. $P$. gingivalis has also been detected with immunohistochemistry from gingival OSCC, and orodigestive cancer mortality is related to high $P$. gingivalis antibody levels $[141,149]$. Nonetheless, there is a need for studies showing causal evidence and population-based epidemiological evidence of the association of these bacteria with OSCC. Bacteria can also be detected as part of a secondary colonization to the tumor site because of a lowered immune defence due to the carcinoma itself [150]. Welldesigned follow-up studies are still lacking.

Alterations in oral cavity bacterial microbiota to more pathogenic microbes in addition to known etiological factors, smoking, and alcohol consumption contribute to oral carcinogenesis [151]. Thanks to the achievements of future research, there might be possibilities to manage known possibly carcinogenic bacteria with personalized medicine, such as phage therapy $[152,153]$. In the meantime, mechanical biofilm disruption and good oral hygiene are essential in preventing harmful bacteria from colonizing the oral cavity. Furthermore, avoiding alcohol and tobacco products decreases the exposure to acetaldehyde production directly or indirectly by oral cavity bacteria.

\section{Conclusions}

It is evident that oral bacteria can have profound effects on human health inside and outside the oral cavity. Oral pathogenic bacteria can have indirect or direct effects on the human immune response and affect to normal cell signalling pathways preceding carcinoma development. Since the onset of carcinoma development is a complex and time-consuming procedure, it is difficult to determine the causal relationship between oral cavity bacteria and carcinoma development. However, it is known that certain oral pathogens, such as $P$. gingivalis and $F$. nucleatum, can promote pathways that might trig- 
ger carcinoma development. Nonetheless, it is important to understand that in the human body the microbiota works synergistically and one bacterium cannot determinate the entity. We need more research to truly understand the complex mechanisms behind the impact of bacterial microbiota on cancer development.

\section{Conflict of Interest Statement}

The authors declare that they have no competing interests.

\section{References}

1 Gilbert JA, Neufeld JD. Life in a world without microbes. PLoS Biol. 2014 Dec; 12(12): 1002020

2 Wang B, Yao M, Lv L, Ling Z, Li L. The human microbiota in health and disease. Engineering. 2017 Feb;3(1):71-82.

3 Petersen C, Round JL. Defining dysbiosis and its influence on host immunity and disease. Cell Microbiol. 2014 Jul;16(7):1024-33.

4 Bäckhed F, Fraser CM, Ringel Y, Sanders ME, Sartor RB, Sherman PM, et al. Defining a healthy human gut microbiome: current concepts, future directions, and clinical applications. Cell Host Microbe. 2012 Nov; 12(5): 611-22.

5 Hsiao EY, McBride SW, Hsien S, Sharon G, Hyde ER, McCue T, et al. Microbiota modulate behavioral and physiological abnormalities associated with neurodevelopmental disorders. Cell. 2013 Dec;155(7):1451-63.

6 Trompette A, Gollwitzer ES, Yadava K, Sichelstiel AK, Sprenger N, Ngom-Bru C, et al. Gut microbiota metabolism of dietary fiber influences allergic airway disease and hematopoiesis. Nat Med. 2014 Feb;20(2):159-66.

7 Garrett WS. Cancer and the microbiota. Science. 2015 Apr;348(6230):80-6.

8 Karpiński TM. Role of oral microbiota in cancer development. Microorganisms. 2019 Jan; 7(1):E20.

9 Kowalski K, Mulak A. Brain-gut-microbiota axis in Alzheimer's disease. J Neurogastroenterol Motil. 2019 Jan;25(1):48-60.

10 Turnbaugh PJ, Hamady M, Yatsunenko T, Cantarel BL, Duncan A, Ley RE, et al. A core gut microbiome in obese and lean twins. $\mathrm{Na}$ ture. 2009 Jan;457(7228):480-4.

11 Huttenhower C, Kostic AD, Xavier RJ. Inflammatory bowel disease as a model for translating the microbiome. Immunity. 2014 Jun;40(6):843-54.

12 Ursell LK, Metcalf JL, Parfrey LW, Knight R. Defining the human microbiome. Nutr Rev. 2012 Aug;70:S38-44.

13 Huttenhower C, Gevers D, Knight R, Abubucker S, Badger JH, Chinwalla AT, et al.; Human Microbiome Project Consortium. Structure, function and diversity of the healthy human microbiome. Nature. 2012 Jun; 486(7402):207-14.

14 Lloyd-Price J, Abu-Ali G, Huttenhower C. The healthy human microbiome. Genome Med. 2016 Apr;8(1):51.
15 Collado MC, Rautava S, Aakko J, Isolauri E, Salminen S. Human gut colonisation may be initiated in utero by distinct microbial communities in the placenta and amniotic fluid. Sci Rep. 2016 Mar;6(1):23129.

16 Jiménez E, Marín ML, Martín R, Odriozola $\mathrm{JM}$, Olivares $\mathrm{M}$, Xaus J, et al. Is meconium from healthy newborns actually sterile? Res Microbiol. 2008 Apr;159(3):187-93.

17 Tuominen H, Collado MC, Rautava J, Syrjänen S, Rautava S. Composition and maternal origin of the neonatal oral cavity microbiota. J Oral Microbiol. 2019 Sep;11(1):1663084.

18 Dominguez-Bello MG, Costello EK, Contreras M, Magris M, Hidalgo G, Fierer N, et al. Delivery mode shapes the acquisition and structure of the initial microbiota across multiple body habitats in newborns. Proc Natl Acad Sci USA. 2010 Jun;107(26):11971-5.

19 Lif Holgerson P, Harnevik L, Hernell O, Tanner AC, Johansson I. Mode of birth delivery affects oral microbiota in infants. J Dent Res. 2011 Oct;90(10):1183-8.

20 Dzidic M, Collado MC, Abrahamsson T, Artacho A, Stensson M, Jenmalm MC, et al. Oral microbiome development during childhood: an ecological succession influenced by postnatal factors and associated with tooth decay. ISME J. 2018 Sep;12(9):2292-306.

21 Aujoulat F, Roudière L, Picaud JC, Jacquot A, Filleron A, Neveu D, et al. Temporal dynamics of the very premature infant gut dominant microbiota. BMC Microbiol. 2014 Dec;14(1): 325.

22 Mueller NT, Bakacs E, Combellick J, Grigoryan Z, Dominguez-Bello MG. The infant microbiome development: mom matters. Trends Mol Med. 2015 Feb;21(2):109-17.

23 Blaser MJ, Dominguez-Bello MG. The human microbiome before birth. Cell Host Microbe. 2016 Nov;20(5):558-60.

24 Dominguez-Bello MG, De Jesus-Laboy KM, Shen N, Cox LM, Amir A, Gonzalez A, et al. Partial restoration of the microbiota of cesarean-born infants via vaginal microbial transfer. Nat Med. 2016 Mar;22(3):250-3.

25 Nuriel-Ohayon M, Neuman H, Koren O. Microbial changes during pregnancy, birth, and infancy. Front Microbiol. 2016 Jul;7:1031.

26 Chong CY, Bloomfield FH, O'Sullivan JM. Factors affecting gastrointestinal microbiome development in neonates. Nutrients. 2018 Feb;10(3):274.
27 Jakobsson HE, Abrahamsson TR, Jenmalm MC, Harris K, Quince C, Jernberg C, et al. Decreased gut microbiota diversity, delayed Bacteroidetes colonisation and reduced Th1 responses in infants delivered by caesarean section. Gut. 2014 Apr;63(4):559-66.

28 Lif Holgerson P, Öhman C, Rönnlund A, Johansson I. Maturation of Oral Microbiota in Children with or without Dental Caries. PLoS One. 2015 May;10(5):e0128534.

29 Zaura E, Nicu EA, Krom BP, Keijser BJ. Acquiring and maintaining a normal oral microbiome: current perspective. Front Cell Infect Microbiol. 2014 Jun;4:85.

30 Dewhirst FE, Chen T, Izard J, Paster BJ, Tanner AC, Yu WH, et al. The human oral microbiome. J Bacteriol. 2010 Oct;192(19):5002-17.

31 Kilian M, Chapple IL, Hannig M, Marsh PD, Meuric V, Pedersen AM, et al. The oral microbiome - an update for oral healthcare professionals. Br Dent J. 2016 Nov;221(10):657-66.

32 Sender R, Fuchs S, Milo R. Revised estimates for the number of human and bacteria cells in thebody. PLoS Biol.2016 Aug;14(8):e1002533.

33 Damgaard C, Reinholdt J, Enevold C, Fiehn NE, Nielsen CH, Holmstrup P. Immunoglobulin $\mathrm{G}$ antibodies against Porphyromonas gingivalis or Aggregatibacter actinomycetemcomitans in cardiovascular disease and periodontitis. J Oral Microbiol. 2017 Sep;9(1): 1374154.

34 Koziel J, Mydel P, Potempa J. The link between periodontal disease and rheumatoid arthritis: an updated review. Curr Rheumatol Rep. 2014 Mar; 16(3):408.

35 Aas JA, Paster BJ, Stokes LN, Olsen I, Dewhirst FE. Defining the normal bacterial flora of the oral cavity. J Clin Microbiol. 2005 Nov; 43(11):5721-32.

36 Janket SJ, Baird AE, Chuang SK, Jones JA. Meta-analysis of periodontal disease and risk of coronary heart disease and stroke. Oral Surg Oral Med Oral Pathol Oral Radiol Endod. 2003 May;95(5):559-69.

37 Petersen PE. Oral cancer prevention and control: the approach of the World Health Organization. Oral Oncol. 2009 Apr-May;45(4-5): 454-60.

38 Bray F, Ferlay J, Soerjomataram I, Siegel RL, Torre LA, Jemal A. Global cancer statistics 2018: GLOBOCAN estimates of incidence and mortality worldwide for 36 cancers in 185 countries. CA Cancer J Clin. 2018 Nov;68(6): 394-424. 
39 Mroueh R, Haapaniemi A, Grénman R, Laranne J, Pukkila M, Almangush A, et al. Improved outcomes with oral tongue squamous cell carcinoma in Finland. Head Neck. 2017 Jul;39(7):1306-12.

40 Vázquez-Mahía I, Seoane J, Varela-Centelles P, Tomás I, Álvarez García A, López Cedrún JL. Predictors for tumor recurrence after primary definitive surgery for oral cancer. J Oral Maxillofac Surg. 2012 Jul;70(7):1724-32.

41 van Oijen MG, Slootweg PJ. Oral field cancerization: carcinogen-induced independent events or micrometastatic deposits? Cancer Epidemiol Biomarkers Prev. 2000 Mar;9(3): 249-56.

42 Kantola S, Jokinen K, Hyrynkangas K, Mäntyselkä P, Alho OP. Detection of tongue cancer in primary care. Br J Gen Pract. 2001 Feb; 51(463):106-11.

43 Rogers SN, Vedpathak SV, Lowe D. Reasons for delayed presentation in oral and oropharyngeal cancer: the patients perspective. $\mathrm{Br}$ J Oral Maxillofac Surg. 2011 Jul;49(5):349-53.

44 Abu-Ghanem S, Yehuda M, Carmel NN, Leshno M, Abergel A, Gutfeld O, et al. Elective neck dissection vs observation in earlystage squamous cell carcinoma of the oral tongue with no clinically apparent lymph node metastasis in the neck a systematic review and meta-Analysis. JAMA Otolaryngol Head Neck Surg. 2016 Sep;142(9):857-65.

45 Ding Z, Xiao T, Huang J, Yuan Y, Ye Q, Xuan $\mathrm{M}$, et al. Elective neck dissection versus observation in squamous cell carcinoma of oral cavity with clinically N0 neck: A systematic review and meta-analysis of prospective studies. J Oral Maxillofac Surg. 2019 Jan;77(1): $184-94$.

46 Jerjes W, Upile T, Petrie A, Riskalla A, Hamdoon Z, Vourvachis M, et al. Clinicopathological parameters, recurrence, locoregional and distant metastasis in $115 \mathrm{~T} 1-\mathrm{T} 2$ oral squamous cell carcinoma patients. Head Neck Oncol. 2010 Apr;2(1):9.

47 Chocolatewala N, Chaturvedi P, Desale R. The role of bacteria in oral cancer. Indian J Med Paediatr Oncol. 2010 Oct;31(4):126-31.

48 Koray M, Tosun T. Oral mucosal trauma and injuries. IntechOpen; 2019. Available from: https://doi.org/10.5772/intechopen.81201

49 Deo PN, Deshmukh R. Pathophysiology of keratinization. J Oral Maxillofac Pathol. 2018 Jan-Apr;22(1):86-91.

50 Costalonga M, Herzberg MC. The oral microbiome and the immunobiology of periodontal disease and caries. Immunol Lett. 2014 Dec; 162:22-38.

51 Koliarakis I, Messaritakis I, Nikolouzakis TK, Hamilos G, Souglakos J, Tsiaoussis J. Oral bacteria and intestinal dysbiosis in colorectal cancer. Int J Mol Sci. 2019 Aug;20(17):4146.

52 Könönen E, Gursoy M, Gursoy UK. Periodontitis: A multifaceted disease of toothsupporting tissues. J Clin Med. 2019 Jul;8(8) 1135.
53 Van'T Hof W. Veerman ECI, Amerongen AVN, Ligtenberg AJM. Antimicrobial defense systems in saliva. Monogr Oral Sci. 2014;24:40-51.

54 Marsh PD, Do T, Beighton D, Devine DA. Influence of saliva on the oral microbiota. Periodontol 2000. 2016 Feb;70(1):80-92.

55 Huse SM, Ye Y, Zhou Y, Fodor AA. A core human microbiome as viewed through $16 \mathrm{~S}$ rRNA sequence clusters. PLoS One. 2012; 7(6):e34242.

56 Wade WG. The oral microbiome in health and disease. Pharmacol Res. 2013 Mar;69(1): $137-43$.

57 Chattopadhyay I, Verma M, Panda M. Role of oral microbiome signatures in diagnosis and prognosis of oral cancer. Technol Cancer Res Treat. 2019 Jan;18:1533033819867354.

58 Gao L, Xu T, Huang G, Jiang S, Gu Y, Chen F. Oral microbiomes: more and more importance in oral cavity and whole body. Protein Cell. 2018 May;9(5):488-500.

59 Do T, Devine D, Marsh PD. Oral biofilms: molecular analysis, challenges, and future prospects in dental diagnostics. Clin Cosmet Investig Dent. $2013 \mathrm{Feb} ; 5: 11-9$.

60 Könönen E, Paju S, Pussinen PJ, Hyvönen M Di Tella P, Suominen-Taipale L, et al. Population-based study of salivary carriage of periodontal pathogens in adults. J Clin Microbiol. 2007 Aug;45(8):2446-51.

61 Kudo Y, Tada H, Fujiwara N, Tada Y, Tsunematsu T, Miyake Y, et al. Oral environment and cancer. Genes Environ. 2016 Aug;38(1): 13.

62 Gholizadeh P, Eslami H, Yousefi M, Asgharzadeh M, Aghazadeh M, Kafil HS. Role of oral microbiome on oral cancers, a review. Biomed Pharmacother. 2016 Dec;84:552-8.

63 Syriänen S. Human papillomavirus (HPV) in head and neck cancer. J Clin Virol. 2005 Mar; 32 Suppl 1:S59-66.

64 Tuominen H, Rautava S, Collado MC, Syrjänen S, Rautava J. HPV infection and bacterial microbiota in breast milk and infant oral mucosa. PLoS One. 2018 Nov;13(11):e0207016.

65 Sampaio-Maia B, Caldas IM, Pereira ML Pérez-Mongiovi D, Araujo R. The oral microbiome in health and its implication in oral and systemic diseases. Adv Appl Microbiol. 2016; 97:171-210

66 Li K, Bihan M, Methé BA. Analyses of the stability and core taxonomic memberships of the human microbiome. PLoS One. 2013 May; 8(5):e63139.

67 Hajishengallis G. The inflammophilic character of the periodontitis-associated microbiota. Mol Oral Microbiol. 2014 Dec;29(6):248-57.

68 Michaud DS, Lu J, Peacock-Villada AY, Barber JR, Joshu CE, Prizment AE, et al. Periodontal disease assessed using clinical dental measurements and cancer risk in the ARIC study. J Natl Cancer Inst. 2018 Aug;110(8): 843-54.

69 Michaud DS, Fu Z, Shi J, Chung M. Periodontal disease, tooth loss, and cancer risk. Epidemiol Rev. 2017 Jan;39(1):49-58.
70 Paraskevas S, Huizinga JD, Loos BG. A systematic review and meta-analyses on C-reactive protein in relation to periodontitis. J Clin Periodontol. 2008 Apr;35(4):277-90.

71 Ebersole JL, Machen RL, Steffen MJ, Willmann DE. Systemic acute-phase reactants, Creactive protein and haptoglobin, in adult periodontitis. Clin Exp Immunol. $1997 \mathrm{Feb}$; 107(2):347-52.

72 Eke PI, Dye BA, Wei L, Thornton-Evans GO Genco RJ; CDC Periodontal Disease Surveillance workgroup. Prevalence of periodontitis in adults in the United States: 2009 and 2010. J Dent Res. 2012 Oct;91(10):914-20.

73 Wang K, Lu W, Tu Q, Ge Y, He J, Zhou Y, et al. Preliminary analysis of salivary microbiome and their potential roles in oral lichen planus. Sci Rep. 2016 Mar;6(1):22943

74 Carrillo-de-Albornoz A, Figuero E, Herrera D, Bascones-Martínez A. Gingival changes during pregnancy. 2. Influence of hormonal variations on the subgingival biofilm. J Clin Periodontol. 2010 Mar;37(3):230-40.

75 Abusleme L, Dupuy AK, Dutzan N, Silva N, Burleson JA, Strausbaugh LD, et al. The subgingival microbiome in health and periodontitis and its relationship with community biomass and inflammation. ISME J. 2013 May; 7(5):1016-25.

76 Diaz PI, Hoare A, Hong BY. Subgingival Microbiome Shifts and Community Dynamics in Periodontal Diseases. J Calif Dent Assoc. 2016 Jul;44(7):421-35.

77 Hajishengallis G, Liang S, Payne MA, Hashim A, Jotwani R, Eskan MA, et al. Low-abundance biofilm species orchestrates inflammatory periodontal disease through the commensal microbiota and complement. Cell Host Microbe. 2011 Nov;10(5):497-506.

78 Michaud DS, Kelsey KT, Papathanasiou E, Genco CA, Giovannucci E. Periodontal disease and risk of all cancers among male never smokers: an updated analysis of the Health Professionals Follow-up Study. Ann Oncol. 2016 May;27(5):941-7.

79 Tezal M, Sullivan MA, Hyland A, Marshall JR, Stoler D, Reid ME, et al. Chronic periodontitis and the incidence of head and neck squamous cell carcinoma. Cancer Epidemiol Biomarkers Prev. 2009 Sep;18(9):2406-12.

80 Moergel M, Kämmerer P, Kasaj A, Armouti E, Alshihri A, Weyer V, et al. Chronic periodontitis and its possible association with oral squamous cell carcinoma: a retrospective case control study. Head Face Med. 2013 Dec;9(1): 39.

81 Corbella S, Veronesi P, Galimberti V, Weinstein R, Del Fabbro M, Francetti L. Is periodontitis a risk indicator for cancer? A metaanalysis. PLoS One. 2018 Apr;13(4):e0195683.

82 Gholizadeh P, Eslami H, Kafil HS. Carcinogenesis mechanisms of Fusobacterium nucleatum. Biomed Pharmacother. 2017 May; 89:918-25.

Tuominen/Rautava 
83 Yao QW, Zhou DS, Peng HJ, Ji P, Liu DS. Association of periodontal disease with oral cancer: a meta-analysis. Tumour Biol. 2014 Jul; 35(7):7073-7.

84 Fitzpatrick SG, Katz J. The association between periodontal disease and cancer: a review of the literature. J Dent. 2010 Feb;38(2): 83-95.

85 Garrote LF, Herrero R, Reyes RM, Vaccarella S, Anta JL, Ferbeye L, et al. Risk factors for cancer of the oral cavity and oro-pharynx in Cuba. Br J Cancer. 2001 Jul;85(1):46-54.

86 Bundgaard T, Wildt J, Frydenberg M, Elbrønd O, Nielsen JE. Case-control study of squamous cell cancer of the oral cavity in Denmark. Cancer Causes Control. 1995 Jan; 6(1):57-67.

87 Atanasova KR, Yilmaz O. Looking in the Porphyromonas gingivalis cabinet of curiosities: the microbium, the host and cancer association. Mol Oral Microbiol. 2014 Apr;29(2):5566.

88 Hajishengallis G. Periodontitis: from microbial immune subversion to systemic inflammation. Nat Rev Immunol. 2015 Jan;15(1): $30-44$.

89 Hoare A, Soto C, Rojas-Celis V, Bravo D. Chronic inflammation as a link between periodontitis and carcinogenesis. Mediators Inflamm. 2019 Mar;2019:1029857.

90 Li X, Kolltveit KM, Tronstad L, Olsen I. Systemic diseases caused by oral infection. Clin Microbiol Rev. 2000 Oct;13(4):547-58.

91 Herrero ER, Fernandes S, Verspecht T, Ugarte-Berzal E, Boon N, Proost P, et al. Dysbiotic biofilms deregulate the periodontal inflammatory response. J Dent Res. 2018 May; 97(5):547-55.

92 Aparna M, Rao L, Kunhikatta V, Radhakrishnan R. The role of MMP-2 and MMP-9 as prognostic markers in the early stages of tongue squamous cell carcinoma. J Oral Pathol Med. 2015 May;44(5):345-52.

93 Geng F, Liu J, Guo Y, Li C, Wang H, Wang H, et al. Persistent exposure to Porphyromonas gingivalis promotes proliferative and invasion capabilities, and tumorigenic properties of human immortalized oral epithelial cells. Front Cell Infect Microbiol. 2017 Feb; 7:57.

94 Yao L, Jermanus C, Barbetta B, Choi C, Verbeke $\mathrm{P}, \mathrm{Ojcius} \mathrm{DM}$, et al. Porphyromonas gingivalis infection sequesters pro-apoptotic $\mathrm{Bad}$ through Akt in primary gingival epithelial cells. Mol Oral Microbiol. 2010 Apr;25(2):89101.

95 Yilmaz O, Jungas T, Verbeke P, Ojcius DM. Activation of the phosphatidylinositol 3-kinase/Akt pathway contributes to survival of primary epithelial cells infected with the periodontal pathogen Porphyromonas gingivalis. Infect Immun. 2004 Jul;72(7):3743-51.

96 Warnakulasuriya S, Johnson NW, van der Waal I. Nomenclature and classification of potentially malignant disorders of the oral mucosa. J Oral Pathol Med. 2007 Nov;36(10): $575-80$.
97 Reichart PA, Schmidt-Westhausen AM, Khongkhunthian P, Strietzel FP. Dental implants in patients with oral mucosal diseases - a systematic review. J Oral Rehabil. 2016 May;43(5):388-99.

98 Lodi G, Scully C, Carrozzo M, Griffiths M, Sugerman PB, Thongprasom K. Current controversies in oral lichen planus: report of an international consensus meeting. Part 1 - viral infections and etiopathogenesis. Oral Surg Oral Med Oral Pathol Oral Radiol Endod. 2005 Jul;100(1):40-51.

99 Mortazavi H, Baharvand M, Mehdipour M. Oral potentially malignant disorders: an overview of more than 20 entities. J Dent Res Dent Clin Dent Prospects. 2014;8(1):6-14.

100 Lodi G, Scully C, Carrozzo M, Griffiths M, Sugerman PB, Thongprasom K. Current controversies in oral lichen planus: report of an international consensus meeting. Part 2 clinical management and malignant transformation. Oral Surg Oral Med Oral Pathol Oral Radiol Endod. 2005 Aug;100(2):164-78.

101 Starzyńska A, Pawłowska A, Renkielska D, Michajłowski I, Sobjanek M, Błażewicz I. Oral premalignant lesions: epidemiological and clinical analysis in the northern Polish population. Adv Dermatol Allergol. 2014 Dec;31(6):341-50.

102 Bäckman K, Jontell M. Microbial-associated oral lichenoid reactions. Oral Dis. 2007 Jul; 13(4):402-6.

103 He Y, Gong D, Shi C, Shao F, Shi J, Fei J. Dysbiosis of oral buccal mucosa microbiota in patients with oral lichen planus. Oral Dis. 2017 Jul;23(5):674-82.

104 Kragelund C, Keller MK. The oral microbiome in oral lichen planus during a 1-year randomized clinical trial. Oral Dis. 2019 Jan 25(1):327-38

105 Bewley AF, Farwell DG. Oral leukoplakia and oral cavity squamous cell carcinoma. Clin Dermatol. 2017 Sep - Oct;35(5):461-7.

106 Johnson NW, Jayasekara P, Amarasinghe AAHK. Squamous cell carcinoma and precursor lesions of the oral cavity: epidemiology and aetiology. Periodontology. 2000 Oct;57(1):19-37.

107 Yanik EL, Katki HA, Silverberg MJ, Manos MM, Engels EA, Chaturvedi AK. Leukoplakia, oral cavity cancer risk, and cancer survival in the US elderly. Cancer Prev Res (Phila). 2015 Sep;8(9):857-63.

108 Amer A, Galvin S, Healy CM, Moran GP. The microbiome of potentially malignant oral leukoplakia exhibits enrichment for $\mathrm{Fu}$ sobacterium, Leptotrichia, Campylobacter, and Rothia species. Front Microbiol. 2017 Dec;8(DEC):2391.

109 Hu X, Zhang Q, Hua H, Chen F. Changes in the salivary microbiota of oral leukoplakia and oral cancer. Oral Oncol. 2016 May; 56:e6-8.

110 Stämpfli MR, Anderson GP. How cigarette smoke skews immune responses to promote infection, lung disease and cancer. Nat Rev Immunol. 2009 May;9(5):377-84.
111 Yu G, Phillips S, Gail MH, Goedert JJ, Humphrys MS, Ravel J, et al. The effect of cigarette smoking on the oral and nasal microbiota. Microbiome. 2017 Jan;5(1):3.

112 Grine G, Royer A, Terrer E, Diallo OO, Drancourt M, Aboudharam G. Tobacco smoking affects the salivary Gram-positive bacterial population. Front Public Health. 2019 Jul;7:196.

113 Lee WH, Chen HM, Yang SF, Liang C, Peng $\mathrm{CY}$, Lin FM, et al. Bacterial alterations in salivary microbiota and their association in oral cancer. Sci Rep. 2017 Nov;7(1):16540.

114 Nakonieczna-Rudnicka M, Bachanek T. Number of Streptococcus mutans and Lactobacillus in saliva versus the status of cigarette smoking, considering duration of smoking and number of cigarettes smoked daily. Ann Agric Environ Med. 2017 Sep; 24(3):396-400.

115 Pushalkar S, Mane SP, Ji X, Li Y, Evans C, Crasta OR, et al. Microbial diversity in saliva of oral squamous cell carcinoma. FEMS Immunol Med Microbiol. 2011 Apr;61(3):26977.

116 Schmidt BL, Kuczynski J, Bhattacharya A, Huey B, Corby PM, Queiroz EL, et al. Changes in abundance of oral microbiota associated with oral cancer. PLoS One. 2014 Jun;9(6):e98741.

117 Nagy KN, Sonkodi I, Szöke I, Nagy E, Newman HN. The microflora associated with human oral carcinomas. Oral Oncol. 1998 Jul;34(4):304-8.

118 Yang CY, Yeh YM, Yu HY, Chin CY, Hsu $\mathrm{CW}$, Liu H, et al. Oral Microbiota community dynamics associated with oral squamous cell carcinoma staging. Front Microbiol. 2018 May;9:862.

119 Zakhari S. Overview: how is alcohol metabolized by the body? Alcohol Res Health. 2006; 29(4):245-54.

120 Secretan B, Straif K, Baan R, Grosse Y, El Ghissassi F, Bouvard V, et al.; WHO International Agency for Research on Cancer Monograph Working Group. A review of human carcinogens - Part E: tobacco, areca nut, alcohol, coal smoke, and salted fish. Lancet Oncol. 2009 Nov; 10(11):1033-4.

121 Moritani K, Takeshita T, Shibata Y, Ninomiya T, Kiyohara Y, Yamashita Y. Acetaldehyde production by major oral microbes. Oral Dis. 2015 Sep;21(6):748-54

122 Homann N, Tillonen J, Rintamäki H, Salaspuro $\mathrm{M}$, Lindqvist $\mathrm{C}$, Meurman JH. Poor dental status increases acetaldehyde production from ethanol in saliva: a possible link to increased oral cancer risk among heavy drinkers. Oral Oncol. 2001 Feb;37(2):153-8.

123 Brierley J, Gospodarowicz MK, Mary K, Wittekind C, editors. TNM classification of malignant tumours. Hoboken: Wiley-Blackwell; 2010.

124 Zhang Y, Wang X, Li H, Ni C, Du Z, Yan F. Human oral microbiota and its modulation for oral health. Biomed Pharmacother. 2018 Mar;99:883-93. 
125 Perera M, Al-Hebshi NN, Speicher DJ, Perera I, Johnson NW. Emerging role of bacteria in oral carcinogenesis: a review with special reference to perio-pathogenic bacteria. J Oral Microbiol. 2016 Sep;8(1):32762.

126 Whitmore SE, Lamont RJ. Oral bacteria and cancer. PLoS Pathog. 2014 Mar; 10(3):e1003933.

127 Vogelmann R, Amieva MR. The role of bacterial pathogens in cancer. Curr Opin Microbiol. 2007 Feb;10(1):76-81.

128 Zhang G, Ghosh S. Molecular mechanisms of NF-kappaB activation induced by bacterial lipopolysaccharide through Toll-like receptors. J Endotoxin Res. 2000;6(6):453-7.

129 Stashenko P, Yost S, Choi Y, Danciu T, Chen $\mathrm{T}$, Yoganathan S, et al. The oral mouse microbiome promotes tumorigenesis in oral squamous cell carcinoma. mSystems. 2019 Aug;4(4):e00323-19.

130 Klimesova K, Jiraskova Zakostelska Z, Tlaskalova-Hogenova H. Oral bacterial and fungal microbiome impacts colorectal carcinogenesis. Front Microbiol. 2018 Apr;9:774.

131 Flemer B, Warren RD, Barrett MP, Cisek K, Das A, Jeffery IB, et al. The oral microbiota in colorectal cancer is distinctive and predictive. Gut. 2018 Aug;67(8):1454-63.

132 Fan X, Alekseyenko AV, Wu J, Peters BA, Jacobs EJ, Gapstur SM, et al. Human oral microbiome and prospective risk for pancreatic cancer: a population-based nested casecontrol study. Gut. 2018 Jan;67(1):120-7.

133 Mascitti M, Togni L, Troiano G, Caponio VC, Gissi DB, Montebugnoli L, et al. Beyond head and neck cancer: The relationship between oral microbiota and tumour development in distant organs. Front Cell Infect Microbiol. 2019 Jun;9:232.

134 Ahn J, Chen CY, Hayes RB. Oral microbiome and oral and gastrointestinal cancer risk. Cancer Causes Control. 2012 Mar; 23(3):399-404.
135 Sheu B-C, Chang W-C, Cheng C-Y, Lin $\mathrm{H}-\mathrm{H}$, Chang D-Y, Huang S-C. Cytokine regulation networks in the cancer microenvironment. Front Biosci. 2008 May;13:6255.

136 Kato I, Vasquez AA, Moyerbrailean G, Land S, Sun J, Lin HS, et al. Oral microbiome and history of smoking and colorectal cancer. J Epidemiol Res. 2016 Oct;2(2):92-101.

137 Yang Y, Cai Q, Shu XO, Steinwandel MD, Blot WJ, Zheng W, et al. Prospective study of oral microbiome and colorectal cancer risk in low-income and African American populations. Int J Cancer. 2019 May;144(10): 2381-9.

138 Michaud DS, Joshipura K, Giovannucci E, Fuchs CS. A prospective study of periodontal disease and pancreatic cancer in US male health professionals. J Natl Cancer Inst. 2007 Jan;99(2):171-5.

139 Farrell JJ, Zhang L, Zhou H, Chia D, Elashoff $\mathrm{D}$, Akin $\mathrm{D}$, et al. Variations of oral microbiota are associated with pancreatic diseases including pancreatic cancer. Gut. 2012 Apr; 61(4):582-8.

140 Torres PJ, Fletcher EM, Gibbons SM, Bouvet M, Doran KS, Kelley ST. Characterization of the salivary microbiome in patients with pancreatic cancer. PeerJ. 2015 Nov;3:e1373.

141 Ahn J, Segers S, Hayes RB. Periodontal disease, Porphyromonas gingivalis serum antibody levels and orodigestive cancer mortality. Carcinogenesis. 2012 May;33(5):1055-8.

142 Michaud DS, Izard J, Wilhelm-Benartzi CS, You DH, Grote VA, Tjønneland A, et al. Plasma antibodies to oral bacteria and risk of pancreatic cancer in a large European prospective cohort study. Gut. 2013 Dec;62(12): 1764-70.

143 Peters BA, Wu J, Pei Z, Yang L, Purdue MP, Freedman ND, et al. Oral microbiome composition reflects prospective risk for esophageal cancers. Cancer Res. 2017 Dec;77(23): 6777-87.
144 Narikiyo M, Tanabe C, Yamada Y, Igaki H Tachimori Y, Kato H, et al. Frequent and preferential infection of Treponema denticola, Streptococcus mitis, and Streptococcus anginosus in esophageal cancers. Cancer Sci. 2004 Jul;95(7):569-74.

145 Healy CM, Moran GP. The microbiome and oral cancer: more questions than answers. Oral Oncol. 2019 Feb;89:30-3.

146 Hayes RB, Ahn J, Fan X, Peters BA, Ma Y, Yang L, et al. Association of oral microbiome with risk for incident head and neck squamous cell cancer. JAMA Oncol. 2018 Mar;4(3):358-65.

147 Multhoff G, Molls M, Radons J. Chronic inflammation in cancer development. Front Immunol. 2012 Jan;2:98.

148 Grivennikov SI, Greten FR, Karin M. Immunity, inflammation, and cancer. Cell. 2010 Mar;140(6):883-99.

149 Katz J, Onate MD, Pauley KM, Bhattacharyya I, Cha S. Presence of Porphyromonas gingivalis in gingival squamous cell carcinoma. Int J Oral Sci. 2011 Oct;3(4):209-15.

150 Cummins J, Tangney M. Bacteria and tumours: causative agents or opportunistic inhabitants? Infect Agent Cancer. 2013 Mar; 8(1):11.

151 Gaonkar PP, Patankar SR, Tripathi N, Sridharan G. Oral bacterial flora and oral cancer: the possible link? J Oral Maxillofac Pathol. 2018 May-Aug;22(2):234-8.

$152 \mathrm{Xu} \mathrm{H}, \mathrm{Cao}$ B, Li Y, Mao C. Phage nanofibers in nanomedicine: biopanning for early diagnosis, targeted therapy, and proteomics analysis. Wiley Interdiscip Rev Nanomed Nanobiotechnol. 2020 Jul;12(4):e1623.

153 Cisek AA, Dąbrowska I, Gregorczyk KP, Wyżewski Z. Phage therapy in bacterial infections treatment: One hundred years after the discovery of bacteriophages. Curr Microbiol. 2017 Feb;74(2):277-83. 